\title{
Implementation of a New Kiosk Technology for Blood Pressure Management in a Family Medicine Clinic: from the WWAMI Region Practice and Research Network
}

\author{
Chia-Fang Chung, MBA, Sean A. Munson, PhD, \\ Matthew J. Thompson, MBChB, MPH, DPhil, Laura-Mae Baldwin, MD, MPH, \\ Jeffrey Kaplan, MD, Randall Cline, MBBLSS, and Beverly B. Green, MD, MPH
}

Background: Using a self-service kiosk to measure blood pressure (BP) has the potential to increase patients' awareness of their BP control and free up medical assistant (MA) time. The objective of this study was to evaluate BP kiosk acceptability and usability, as well as its effects on the workflow of patient BP self-measurement in a primary care clinic.

Methods: We used qualitative and quantitative assessments of kiosk implementation via meetings with clinic leaders, focus groups with clinic providers and staff, observations of kiosk users, and surveys of kiosk users at 2 and 8 months.

Results: Most patients were comfortable using the kiosk ( $82 \%$ at 2 months, $87 \%$ at 8 months). Initial provider concerns included accuracy, but most gained confidence after comparing it with other monitors and reviewing the literature supporting its accuracy. Patients and providers saw many benefits: easier BP checks, increased patient engagement, and saved MA time for other tasks. The clinic addressed early concerns (eg, infection control, confusing instructions, perceived loss of personal touch). Most patients $(86 \%)$ supported the clinic continuing to use the kiosks.

Conclusions Providers, staff, and patients adapted to the use of BP kiosks, providing value by engaging patients in their own care and saving MA time. The clinic decided to keep the self-service kiosk after the pilot period. (J Am Board Fam Med 2016;29:620-629.)

Keywords: Ambulatory Care Facilities, Blood Pressure, Blood Pressure Determination, Focus Groups, Hypertension, Patient Participation, Practice-Based Research, Primary Health Care, Surveys \& Questionnaires, Workflow

To provide more efficient and accessible care, primary care clinics are increasingly adopting health-

This article was externally peer reviewed.

Submitted 13 March 2016; revised 25 May 2016; accepted 2 June 2016.

From the Department of Human Centered Desion \& Engineering, University of Washington, Seattle (C-FC, SAM); Department of Family Medicine, University of Washington, Seattle (MJT, L-MB); the Memorial Physicians/Yakima Valley Memorial Hospital, Yakima, WA (JK, RC); and the Group Health Research Institute, Seattle (BBG).

Funding: This project was supported by the University of Washington's Departments of Family Medicine and Human Centered Design \& Engineering, as well as by the National Center for Advancing Translational Sciences of the National Institutes of Health under award UL1TR000423.

Conflict of interest: none declared.

Disclaimer: The content of this article is solely the responsibility of the authors and does not necessarily represent the official views of the National Institutes of Health. centered technologies, including self-service technologies. Self-service "kiosks" are an example and have been used for medication reconciliation, ${ }^{1}$ health education, ${ }^{2}$ and measurement of vital signs. ${ }^{3}$ While kiosks have the potential to save time for both staff and patients, ${ }^{3}$ previous studies caution that implementing them requires thoughtful integration with patient and clinic workflows as well as facilitation and support from clinic staff.

Measurement of blood pressure (BP) is 1 area where new self-service technology has the potential to transform primary care. BP measurement occurs

Corresponding author: Chia-Fang Chung, MBA, Human Centered Design \& Engineering, University of Washington, 428 Seig Hall, Campus Box 352315, Seattle, WA 98195 (E-mail: cfchung@uw.edu). 
routinely at most health care visits. In recent years, self-measurement in patients' homes has become common, and home and 24-hour ambulatory BP monitoring are more accurate than clinic-based measures in predicting cardiovascular events and death. ${ }^{4}$ Community-based BP measurement using a kiosk, such as those commonly found in pharmacies, is another alternative to clinic-based measurement. ${ }^{5}$ One BP kiosk has been validated as accurate by the Association for the Advancement of Medical Instrumentation standards, ${ }^{6}$ and it has been found to produce results comparable to those of 24-hour ambulatory BP measurement. ${ }^{7}$ However, despite the potential for such kiosks to replace or supplement usual BP measures in primary care clinics, few have been introduced into this setting.

To understand the process of adopting BP kiosk technology, we partnered with a family medicine clinic and used a longitudinal, mixed-methods approach to explore the barriers and facilitators to implementation. We used the Consolidated Framework for Implementation Research (CFIR) ${ }^{8}$ to guide our assessment of contextual factors that might influence the adoption of new workflows associated with BP kiosk use in primary care.

\section{Methods \\ Study Setting}

The study was conducted in a primary care clinic serving a small city and its outlying rural populations in Washington state. The clinic had 6 physicians, 1 physician assistant, 8 medical assistants (MAs), and 5 front desk staff, and it is part of a larger health system that includes a hospital and 4 other primary care clinics. The health system shares a quality improvement (Lean Six Sigma) team that helps to plan and evaluate clinic changes.

The clinic is a member of the WWAMI region Practice and Research Network, a group of $>50$ primary care clinics in 5 Northwestern states committed to collaborating with academic investigators on research that improves clinical practice. The investigators contacted clinic leadership about the opportunity to implement a self-service BP kiosk. These leaders agreed to participate based on their interest in ensuring accurate BP measures throughout the clinic and in determining whether BP kiosk use shortens MA "rooming time," allowing MAs to use that time to complete other clinic duties. Clinic leadership met with their Lean Six Sigma team to plan BP kiosk implementation and assessment.
In August 2014, the clinic installed 2 BP kiosks in the waiting room: 1 close to the front desk and 1 at the far end of the waiting room. The BP kiosk (PharmaSmart PS-2000; PharmaSmart, Rochester, NY) is cleared by the US Food and Drug Administration and is designed to be used without the help of a health professional. The BP kiosk obtains measurements with the individual seated to allow the feet to be placed on the floor and the arm supported at heart level, and it uses a patented cuff technology that automatically adjusts to fit $97 \%$ of arm sizes. The BP kiosk has been validated as accurate compared with mercury manometer measurements ${ }^{6}$ and 24-hour ambulatory BP monitoring. ${ }^{7}$ The kiosk provides patients with a $\mathrm{BP}$ measurement printout and their classification according to the Seventh Report of the Joint National Committee on Prevention, Detection, Evaluation, and Treatment of High Blood Pressure (JNC7). ${ }^{9}$

The clinic adopted an electronic health record (EHR) in 2000 and a computerized patient selfservice check-in to collect profile information and for billing using a Phreesia tablet (Phreesia, New York City, NY) in 2014. Patients use the tablet at check-in to confirm their personal information (eg, address, insurance) and pay their medical bill, a process that takes 5 to 10 minutes the first time and 2 to 3 minutes at subsequent visits. Our evaluation focused on the BP kiosk only.

\section{Study Design and Data Collection}

The multidisciplinary study team, including primary care physicians, human-centered design experts, and quality improvement experts, used a longitudinal mixed-methods approach to evaluate provider (physicians, physician assistants), staff (MAs, front desk staff), clinic leadership, and patient perspectives and experience of the first 9 months of BP kiosk use (August 2014 through April 2015; Table 1). The University of Washington Human Subjects Division approved the study design.

\section{Provider, Staff, and Clinic Leadership Data Collection}

Focus group sessions were conducted with providers, MAs, and front desk staff during the second and eighth months of kiosk implementation. At each time, we held 2 groups. One included providers and MAs, the other MAs and front desk staff (for focus group questions, see Appendix 1). Each group included 8 to 10 participants. All meetings were audio recorded and transcribed. 
Table 1. Timeline of Data Collection throughout Blood Pressure (BP) Kiosk Adoption

\begin{tabular}{|c|c|c|c|c|c|c|c|c|c|}
\hline \multirow{3}{*}{ Data Collection } & \multicolumn{9}{|c|}{ Kiosk Adoption Process } \\
\hline & \multirow[t]{2}{*}{ Planning (6 Months) } & \multicolumn{8}{|c|}{ Deployment (Months) } \\
\hline & & 1 & 2 & 3 & 4 & 5 & 6 & 7 & 8 \\
\hline \multicolumn{10}{|c|}{ Provider, staff, and clinic leader perspectives } \\
\hline Planning meeting observation & $\mathrm{X}$ & & & & & & & & \\
\hline Lean Six Sigma team status update & & $\mathrm{X}$ & $\mathrm{X}$ & $\mathrm{X}$ & & & & $\mathrm{X}$ & \\
\hline Focus group sessions & & & $\mathrm{X}$ & & & & & & $\mathrm{X}$ \\
\hline \multicolumn{10}{|l|}{ Patient perspectives } \\
\hline Clinic observations & & & $\mathrm{X}$ & & & & & & $\mathrm{X}$ \\
\hline Patient surveys & & & $\mathrm{X}$ & & & & & & $\mathrm{X}$ \\
\hline \multicolumn{10}{|l|}{ Patient rooming time } \\
\hline Lean Six Sigma team observations & $\mathrm{X}$ & & & & $\mathrm{X}$ & & & & \\
\hline \multicolumn{10}{|l|}{ BP data } \\
\hline Vendor Reports & & $\mathrm{X}$ & $\mathrm{X}$ & $\mathrm{X}$ & $\mathrm{X}$ & $\mathrm{X}$ & $\mathrm{X}$ & $\mathrm{X}$ & $\mathrm{X}$ \\
\hline
\end{tabular}

\section{Patient Data Collection}

One researcher (C-FC) spent 18 hours over 4 days in the clinic observing kiosk patient use and workflow in the waiting room. Although the observations were focused on patient kiosk experience (60 patients in month 2 and 92 patients in month 8), they also included patient, receptionist, and MA kiosk interactions.

Approximately 2 and 8 months after kiosk implementation, front desk staff gave adult patients attending clinic visits a 4-page anonymous questionnaire and asked them to return it to a closed collection box. The collection box was emptied daily until at least 100 responses were obtained (roughly 2 to 3 weeks). The clinic collected 103 questionnaires during the first survey and 125 during the second survey.

Both questionnaires (see Appendices 2 and 3) included questions using Likert-type scales and openended questions that asked the patients whether they used the kiosk, how comfortable and confident they were in using it (eg, using a 5-option scale, from very comfortable to not at all comfortable), what they liked, what could have improved their experience, and how accurate they thought the kiosk was. The clinic placed a receptionist in the waiting room to help patients use the kiosk and the self-service check-in tablet between the 2 surveys, so the second survey asked about patients' experience with the receptionist in the waiting room and whether the clinic should keep the kiosk.

\section{Rooming Time and BP Data}

The Lean Six Sigma team evaluated MA rooming time before and after BP kiosk implementation. A member of the Lean Six Sigma team used a stopwatch to track the amount of time it took for the MA to greet the patient and prepare the patient in the examination room for a clinic visit (292 patients before and 370 patients after BP kiosk implementation).

The PharmaSmart BP kiosk is web enabled and anonymously collected all BP measurements each time it was used. The kiosk vendor provided the clinic and researchers with monthly reports of the number of BP measurements taken and the percentages categorized as normal, prehypertension, stage 1 hypertension, and stage 2 hypertension (based on JNC7). 9

\section{Analysis}

The research team analyzed the notes from the planning sessions and the transcripts from the 2-month focus groups using a grounded theory approach to identify emerging themes. These themes were then augmented based on analysis of transcripts from the 8-month focus groups. The final themes combined those from the 2 sets of transcripts and were used to analyze notes from observations of kiosk use. We analyzed the patient questionnaires using descriptive statistics such as frequencies, and we used $\chi^{2}$ tests to compare categorical variables between surveys.

\section{Results}

The kiosks recorded 12,525 BP measurements during the first 8 months of deployment. Of these, $28.5 \%$ were categorized as normal, $24.3 \%$ 
Figure 1. Typical workflow after kiosk implementation. BP, blood pressure; MA, medical assistant.

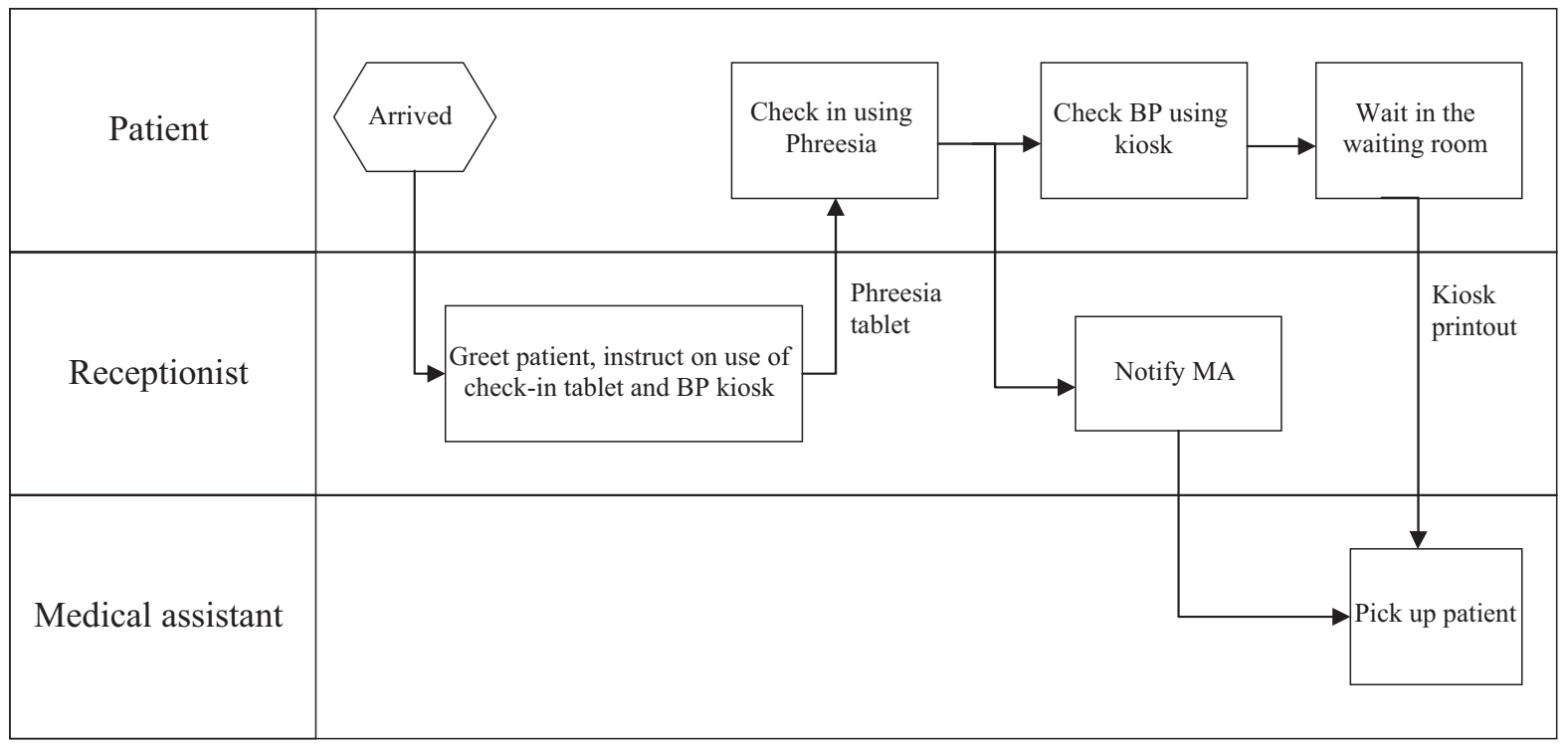

as prehypertension, $34.7 \%$ as stage 1 hypertension, and $12.5 \%$ as stage 2 hypertension. Our observations demonstrated that many patients checked their BP more than once, and based on the timing of the measurements and focus group reports, this seemed to occur more often with high $\mathrm{BP}$ readings.

\section{Typical Workflow After Kiosk Implementation}

We observed that when patients arrived at the clinic's front desk, receptionists greeted them, handed them the tablet for self-check-in, and instructed them on how to use the BP kiosk (Figure 1). The check-in tablet was new to some patients and required receptionists to spend additional time explaining how to use it. After patients used and returned the check-in tablet, receptionists notified the MAs, via the EHR, that the patient had finished check-in. Meanwhile the patient took his or her BP at the kiosk and obtained the paper printout of $\mathrm{BP}$ results. When the MA summoned the patient from the waiting room, the patient handed the $\mathrm{BP}$ printout to the MA.

Clinic staff deviated from this workflow when the clinic was busy or patients were late. For example, receptionists would immediately notify MAs of late arrivals and let patients take the check-in tablet into the examination room. Depending on the purpose of the visit, patients might use the BP kiosk at the end of the visit or the physician or MA would obtain the
$\mathrm{BP}$ in the examination room. During busy times at check-in, patients sometimes queued up to use the kiosk or used the kiosk before completing check-in via the tablet.

\section{Clinic Perspective}

Benefits

Kiosk Use Freed up MA Time. The Lean Six Sigma team's measurements found that MAs spent an average of 1.5 minutes less rooming each patient after the kiosk was introduced. In the focus groups, some MAs confirmed that time savings from patients self-measuring BP were substantial (Table 2, Saves time). MAs reported that the time saved allowed them to spend more time preparing documents and educational materials as well as handling telephone encounters and voicemails.

Kiosk Printout Prompted Provider and Patient Awareness and Engagement with BP. In the focus groups, MAs reported that after entering the BP values into the EHR system, they usually left the kiosk printout for the provider in the examination room. Providers reported that seeing the printout from the kiosk, rather than $\mathrm{BP}$ values in the EHR, increased their attention to the patient's BP (Table 2, Provider awareness).

Many providers and MAs reported that patients paid more attention to their $\mathrm{BP}$ readings and more often noticed when their BP was above normal. This 
Table 2. Focus Group Quotes and their Relationship to Study Themes and the Consolidated Framework of Implementation Research Constructs

Quotes

CFIR Constructs

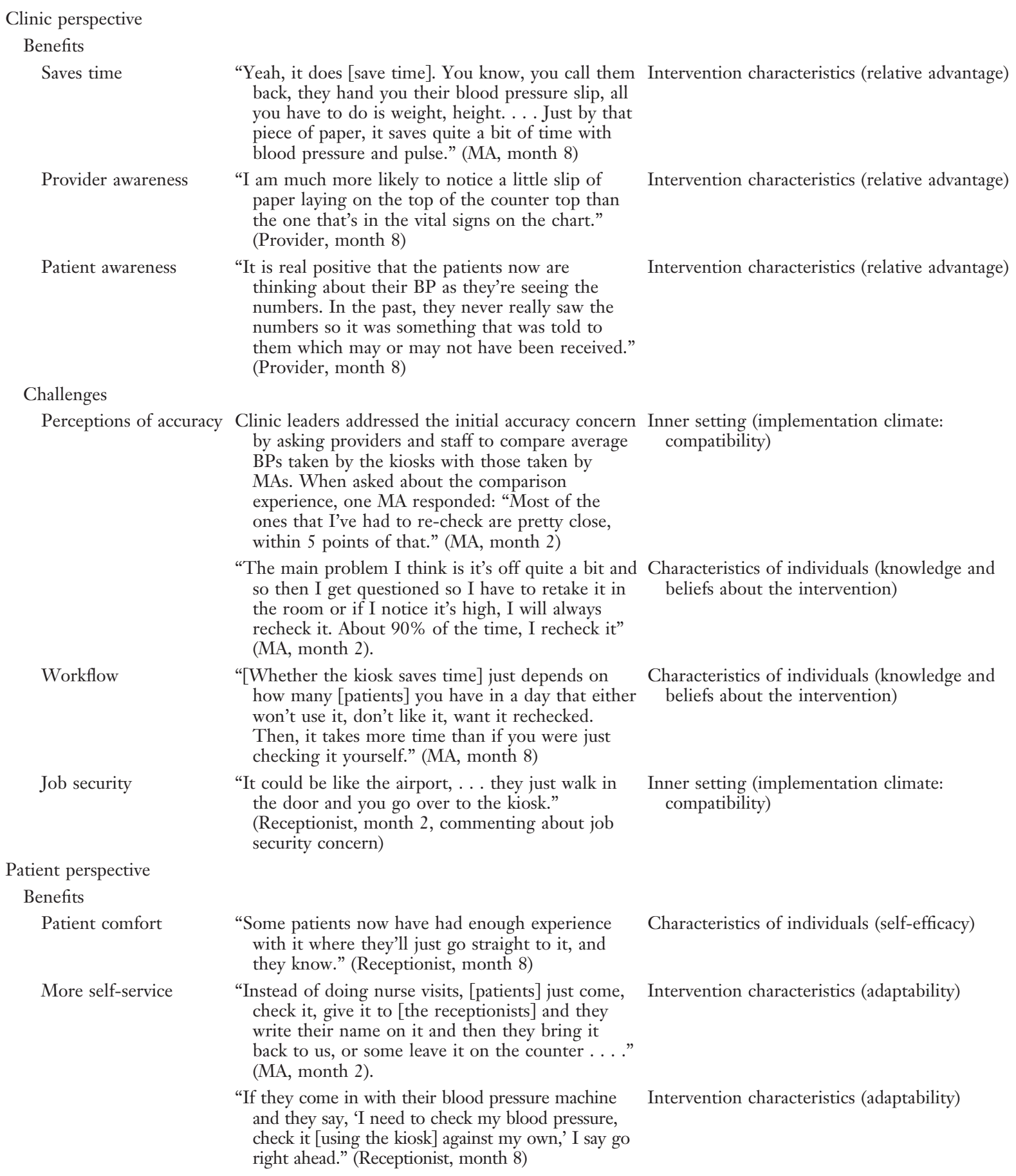




\begin{tabular}{|c|c|c|}
\hline & Quotes & CFIR Constructs \\
\hline \multicolumn{3}{|l|}{ Challenges } \\
\hline $\begin{array}{l}\text { Resting before BP } \\
\text { measurement }\end{array}$ & $\begin{array}{l}\text { "I think that we would get better readings if } \\
\text { the kiosks were located in a different spot, } \\
\text { not in the waiting room. If the patient had } \\
\text { a chance to sit for a few minutes before } \\
\text { they took their blood pressure, be all done } \\
\text { with Phreesia pad so that it was not causing } \\
\text { them anxiety." (Provider, month } 8 \text { ) }\end{array}$ & $\begin{array}{l}\text { Characteristics of individuals (knowledge and } \\
\text { beliefs about the intervention) }\end{array}$ \\
\hline \multirow[t]{2}{*}{ Prehypertension } & $\begin{array}{l}\text { "It's [the prehypertension notation] an } \\
\text { opportunity to enhance some discussion } \\
\text { between us and the patient on what that } \\
\text { means and what steps they can take." } \\
\text { (Provider, month 2) }\end{array}$ & $\begin{array}{l}\text { Inner setting (implementation climate: relative } \\
\text { priority) }\end{array}$ \\
\hline & $\begin{array}{l}\text { "It's not that we don't believe that their blood } \\
\text { pressure should be better, it's just we have } \\
\text { so much competing for our time." } \\
\text { (Provider, month 8). }\end{array}$ & $\begin{array}{l}\text { Inner setting (implementation climate: relative } \\
\text { priority) }\end{array}$ \\
\hline \multirow[t]{2}{*}{ Preferred not to use } & $\begin{array}{l}\text { "We do have people that refuse to use it, } \\
\text { because of so many people, bacteria, } \\
\text { germs." (MA, month 2). }\end{array}$ & $\begin{array}{l}\text { Characteristics of individuals (knowledge and } \\
\text { beliefs about the intervention) }\end{array}$ \\
\hline & $\begin{array}{l}\text { "A lot of them [patients] just want to stand up } \\
\text { there and talk. . . . Before, you know, while } \\
\text { we were checking them in, we could talk to } \\
\text { them, but now we just tell them, you got to } \\
\text { go do this and, I think it's kind of taken } \\
\text { away their social hour." (Receptionist, } \\
\text { month 2). }\end{array}$ & $\begin{array}{l}\text { Characteristics of individuals (knowledge and } \\
\text { beliefs about the intervention) }\end{array}$ \\
\hline
\end{tabular}

BP, blood pressure; CFIR, consolidated framework for implementation research; MA, medical assistant.

seemed to be partly a result of the printout (Table 2, Patient awareness). We observed that some patients kept the printout as a reminder.

Providers and MAs reported that increased awareness of BP measurements sometimes caused patient anxiety. They reported that patients worried about abnormal values, particularly those with BPs in the prehypertension category who had not previously considered their BP as abnormal.

\section{Challenges}

Providers and MAs Had Mixed Perceptions About Kiosk Accuracy. When the clinic first introduced the kiosk, communication with clinic leaders revealed that some providers and clinic staff were concerned about the accuracy of measurements. To address these concerns, clinician leadership and a clinic administrator, the kiosk vendor, and 1 researcher met with clinic providers and staff to present validation studies of the kiosk's accuracy and to answer questions. They encouraged providers and MAs to compare averages of several kiosk measurements with those taken by MAs. Most providers and MAs found that BPs were similar, which increased their trust of kiosk measurements (Table 2, Perceptions of accuracy).

In the focus groups, however, some providers and MAs reported that the kiosks tended to report higher BPs than they expected (Table 2, Perceptions of accuracy). Most MAs and providers reported rechecking BP for $10 \%$ to $20 \%$ of patients, though 1 MA reported that 1 day during the early adoption period she checked or rechecked $80 \%$ because of her concerns about accuracy or differences from an expected BP for a given patient. The rechecks made some staff question whether the kiosk actually saved time (Table 2, Perceptions of accuracy).

Self-service Technology Shifted Work Responsibilities and Created Concerns About Job Security.

To take advantage of the apparent time savings from adopting the kiosks and check-in tablets, the clinic administration reported that they reviewed what clinic staff did with their time. For example, MAs were able to spend more time entering patient medical history following the introduction of the kiosk. 
In focus groups, some clinic staff voiced concern that the clinic would need fewer staff as more tasks became automated, and that kiosk use resulted in less personal service (Table 2, Job security). Clinic leaders reassured staff that their goal was to redirect staff time to improve patient care rather than to reduce staffing.

\section{Patient Perspective Benefits}

Patients Were Comfortable Using the Kiosks. In the 2 - and 8 -month surveys, $82.2 \%$ and $88.8 \%$ of patients, respectively, reported feeling "comfortable" or "very comfortable" using the kiosk. Many patients commented that the kiosk is "convenient," "easy and fast," and that they can "repeat the test" and "do it myself." During our observations 8 months after kiosk deployment, many patients went to the kiosk directly without needing help or instructions, a finding echoed by clinic staff in the focus groups (Table 2, Comfortable using kiosk).

Patients Used Kiosks for More Self-service. Clinic staff reported at focus groups that patients used the kiosks to support other needs, such as between-visit BP checks and home BP monitor calibration. Both staff (in focus groups) and patients (in the survey) reported the kiosk as convenient and a time-saver. Before kiosk deployment, between-visit BP checks often involved making an appointment or waiting until a nurse or MA was available (Table 2, More self-service). In addition, we observed that the kiosk enabled individuals who accompanied patients to check their BPs. Unexpected uses reported in the focus groups and observed in the clinic included patients comparing the results of their own BP devices with those of the kiosk (Table 2, More self-service), as well as clinic providers and staff monitoring their own BPs on the kiosk.

\section{Challenges}

Some Patients Were Concerned About the Accuracy of Kiosk Measurement. While $80 \%$ of patient survey respondents thought kiosk BPs were as accurate or more accurate than those taken by clinic staff, at focus group meetings MAs reported that some patients thought the kiosk BP measurements were higher than expected and were unhappy using the kiosk (Table 2, Perceptions of accuracy). Approximately $40 \%$ of patients in each survey reported that their $\mathrm{BP}$ was retaken by a provider after using the kiosk.

In the focus groups, clinic administrators, providers, and staff discussed the higher-than-expected $\mathrm{BPs}$ and speculated that this might result from patients not having the chance to sit and wait in the reception area before measuring their $\mathrm{BP}$ (Table 2, Perceptions of accuracy). Clinic teams reported that they addressed this by having receptionists instruct patients to relax and take deep breaths before using the kiosk. In the second set of focus groups, the receptionists discussed how they had developed a standard script to encourage patients to take some time before measuring their BP. The 8 -month patient observations reflected patients following these instructions.

Display of Prehypertension Category on Kiosk Printout Caused Confusion. In the focus groups, some providers and MAs reported that some patients were confused and concerned by the prehypertension notations (systolic BP, 120-139; diastolic BP, 80-89) on the kiosk paper printout (Figure 2). Although some providers felt this created an opportunity to educate patients (Table 2, Prehypertension), others felt this was not a good use of their time (Table 2, Prehypertension).

Not Every Patient Could Use the Kiosks. In the focus groups, some providers and clinic staff reported that patients with large or thin arms sometimes had difficulty using the kiosk. When we observed patients with thin arms use the kiosk, the cuff sometimes inflated multiple times but was unable to obtain a measurement. In addition, patients in wheelchairs or those who could not measure BP in their left arm could not use the kiosk. Providers mentioned that they advised patients with specific underlying conditions such as lymphedema or dialysis not to use the kiosk.

Some Patients Preferred Not to Use the Kiosks. In the focus groups, MAs reported that some patients simply preferred not to use the kiosk. At the beginning of kiosk adoption, some of these patient concerns related to hygiene (Table 2, Preferred not to use). In response, the clinic provided wipes for patients to clean the cuff and screen before using the kiosk.

Providers and clinic staff also mentioned that older patients were somewhat more resistant to using the kiosk. They reported that some older 
Figure 2. Blood pressure (BP) kiosk print-out with BP classification.

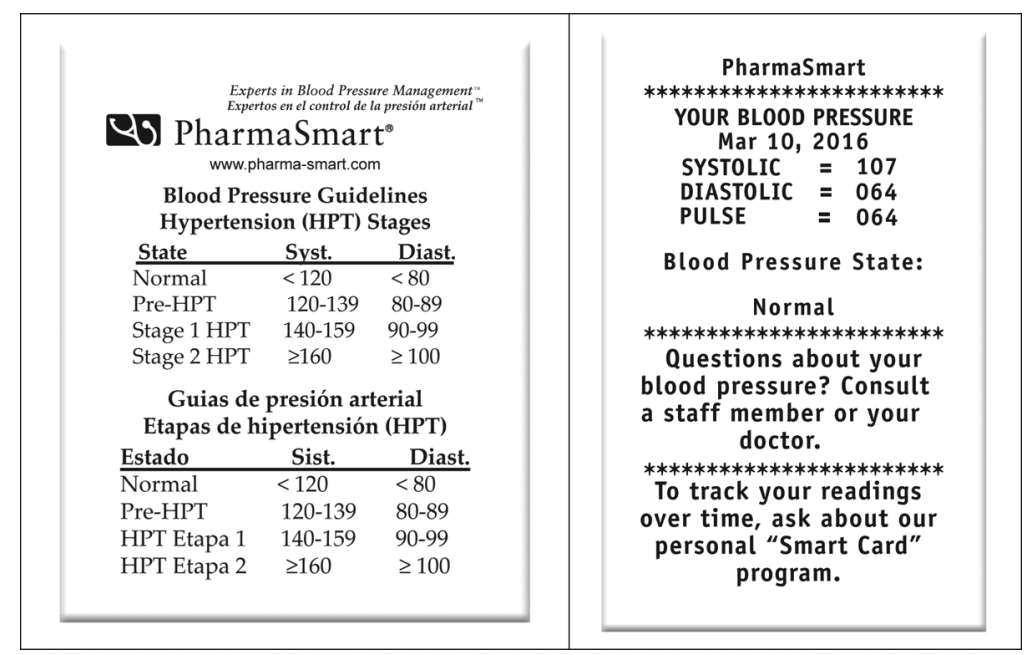

patients seemed to take longer to use the new technology, whereas others felt the self-service technologies were impersonal (Table 2, Preferred not to use).

Clinic staff also reported that some patients had concerns about measuring their $\mathrm{BP}$ in public, in part because of the need to remove an arm from clothing or because of concerns about others seeing their BP readings. We observed that some patients chose to use the kiosk situated in the back of the waiting room, even when the closer one was available. A few patients mentioned in the survey that they would prefer the kiosk be "in a private area."

\section{Adaptations and Further Opportunities for Improvement}

Clinic administrators created a new role-a navigator-to assist patients with the new self-service technologies. The clinic felt that this might help reassure patients that the clinic was using the time and resources saved to provide better quality or more personal care.

The clinic administrative team also was concerned that kiosk placement in the reception area may have contributed to privacy concerns and to higher BP measurements (as patients did not have time to relax after entering the clinic, as recommended by BP measurement experts). The clinic team discussed moving the kiosks closer to the examination rooms to allow patients more time to rest before BP measurement. However, this would have limited kiosk use for BP self-checks, home BP machine calibration, and BP checks by others (eg, family). Relocating the kiosk to other areas might also create new workflow challenges, so the clinic did not make this change.

\section{Discussion}

Clinic personnel and patients identified many benefits to using the BP kiosks, including time saved rooming patients and opportunities for MAs to focus on other aspects of clinical care. Successful adoption required addressing concerns that arose during the implementation process and making modifications to the kiosk, to workflows, and to staff roles. We use the $\mathrm{CFIR}^{8}$ to guide our discussion of the contextual factors that seemed to influence adoption of the BP kiosks. CFIR allowed us to organize information gathered from our mixedmethods, longitudinal evaluation to guide clinic administrators, clinicians, health information technology designers, and researchers regarding the implementation of similar technologies in primary care settings.

\section{Barriers to and Facilitators of BP Kiosk Adoption}

Our findings suggest that the adoption of new technologies in clinical settings is an iterative process that requires ongoing attention to the setting, individuals in that setting, and barriers and concerns that emerge. One barrier was individual knowledge of and belief in the intervention itself (characteristics of individuals, CFIR). Some staff and patients perceived the technology as inaccurate and impersonal. However, the clinic was able to respond to 
concerns quickly and addressed them through formal, Lean Six Sigma rapid cycle evaluation processes. For example, the clinic team addressed the accuracy concern by implementing standard patient instructions before $\mathrm{BP}$ measurement. The use of this reflection and evaluation process (process, CFIR) was highly valuable for implementation of the BP kiosks. The clinic also had strong leadership engagement and resources to support the adaptation process (inner setting, CFIR). Clinic leadership involved providers and staff in this process to identify problems and brainstorm solutions, which contributed to a positive implementation climate (inner setting and trialability, CFIR).

Overall, patients were very positive about the clinic keeping the kiosk. For most patients, the kiosks were easy and convenient to use and provided a way for them to efficiently monitor their BP. From the clinic perspective, the kiosk not only saved MA time but also increased provider engagement and provided opportunities for better BP monitoring and patient education. While some patients felt kiosks were impersonal, the clinic identified opportunities to provide a more personal experience, such as allowing MAs to spend more time taking patient histories and placing the navigator in the waiting room. Provider and MA endorsement of the kiosk also increased patient acceptance.

Our mixed-methods approach allowed us to understand the technology adoption process from the perspectives of both patients and the entire health care team over a period of 8 months. However, our study was conducted in a single primary care clinic with 1 particular self-service technology and may not be generalizable to all clinics or technologies. Around the time of BP kiosk adoption, the clinic also adopted the check-in tablet, which might have affected the kiosk adoption process. Kiosk adoption is an ongoing process, and the navigator in the waiting area was added toward the end of our evaluation. Therefore we were not able to observe and report on all adaptations made in response to this new technology.

\section{Implications for Technology Adoption in Primary Care Clinics}

Although patients were the primary users of this self-service technology, our study highlights that the kiosks influenced both provider and staff workflow. This creates a unique challenge for technology design. Technology designers and developers must consider the interaction between different roles within a primary care setting and how the introduction of a new technology can affect those roles and the relationships between people. Field evaluation is essential, and modifications based on specific workflows are often required as the technology adoption progresses over a period of time.

As self-service technology becomes more prevalent in primary care settings, patients will have more opportunities to encounter information tasks (eg, updating medications) or measurement tasks (eg, BP measurement) originally designed to be performed and interpreted by health care professionals. When this happens, the task or the information generated from these tasks become a "boundary object"10 that bridges the worlds of patient self-management and clinical care. Even something as simple as the design of a paper slip displaying a BP measurement has many opportunities. During this study, these slips prompted patient awareness of their BP status but also generated concerns, confusion, and anxiety. Similar to the OpenNotes initiative, ${ }^{11,12}$ researchers studying technology adoption in clinic settings should be attentive to the impact it may have on interactions between patients and providers.

\section{Implications for Blood Pressure Practice and Research}

There may be other advantages to adopting BP kiosks in clinic settings. There is increasing evidence that BPs obtained at individual clinic visits offer "snapshots" of a patient's BP and may not reflect true (or average) BP, potentially resulting in both under- and overdiagnosis of hypertension and difficulty assessing BP control. ${ }^{13,14}$ Use of BP kiosks might provide more opportunities to efficiently capture additional BPs.

The BP kiosk used in this study has been cleared by the US Food and Drug Administration and the World Hypertension Society, ${ }^{15}$ and has been validated against both the mercury standard ${ }^{6}$ and 24hour ambulatory BP monitoring. ${ }^{7}$ However, simple factors such as patients rushing to obtain BPs when they first enter the clinic may contribute to perceived inaccuracy. Because the BP kiosk is designed for use without the need for health professional supervision, it is difficult to monitor how patients use it or ensure that use is consistent with guidelines for use. For example, we observed that patients often rested for less than the 5 minutes that 
the JNC7 recommends. Clinical staff measuring patients' $\mathrm{BP}$ also are often not compliant with these recommendations. One study found that only $16 \%$ of MAs self-reported that they wait the recommended 5 minutes each time they measured BP. ${ }^{16}$ Providing patients with specific instructions to rest or being able to set kiosk timing might help busy practices adhere to guideline recommendations.

Our study describes implementation of a self-service $\mathrm{BP}$ kiosk in a family medicine clinic. It was not intended to validate the accuracy of the BP kiosk. We present lessons that could be applied to the adoption of other new technologies in primary care settings. The difference between JNC7 guidelines for BP measurement and how patients use a kiosk in practice demonstrate the need for more studies of how best to integrate self-service technologies into clinical workflows. In addition, questions remain about how best to integrate self-service data into EHRs and clinical decision support tools. Newer kiosk models now have the ability to upload BPs directly into an EHR; others have incorporated weight scales and touch screens for patients to enter data. Additional functionality not only provides opportunities for improving care but also creates a need for ongoing evaluation of implementation.

The authors thank Chris Reed and Douglas Southard for their support in planning and implementing this project, as well as in gathering evaluation data; the staff and providers at the participating clinic for their willingness to incorporate a new innovation and its accompanying workflows; Carie Cox for her support in submitting the initial institutional review board application; Malaika Schwartz for her analysis of the patient survey; PharmaSmart for donating the BP kiosks to the clinics during the pilot study; and Josh Sarkis, PharmaSmart Senior Vice President, for his assistance in securing the BP kiosks.

\section{References}

1. Lesselroth BJ, Holahan PJ, Adams K, et al. Primary care provider perceptions and use of a novel medication reconciliation technology. Inform Prim Care 2011;19:105-18.

2. Chan Y-YF, Nagurka R, Bentley S, Ordonez E, Sproule W. Medical utilization of kiosks in the delivery of patient education: a systematic review. Health Promot Perspect 2014;4:1-8.

3. Lowe C, Cummin D. The use of kiosk technology in general practice. J Telemed Telecare 2010;16:201-3.

4. Niiranen TJ, Hänninen MR, Johansson J, Reunanen A, Jula AM. Home-measured blood pressure is a stronger predictor of cardiovascular risk than office blood pressure: the Finn-Home study. Hypertension 2010;55:1346-51.
5. Fleming S, Atherton H, McCartney D, et al. Selfscreening and non-physician screening for hypertension in communities: a systematic review. Am J Hypertens 2015;28:1316-24.

6. Alpert BS. Validation of the Pharma-Smart PS-2000 public use blood pressure monitor. Blood Press Monit 2004;9:19-23.

7. Padwal RS, Townsend RR, Trudeau L, Hamilton PG, Gelfer M. Comparison of an in-pharmacy automated blood pressure kiosk to daytime ambulatory blood pressure in hypertensive subjects. J Am Soc Hypertens 2015;9:123-9.

8. Damschroder LJ, Aron DC, Keith RE, Kirsh SR, Alexander JA, Lowery JC. Fostering implementation of health services research findings into practice: a consolidated framework for advancing implementation science. Implement Sci 2009;4:50.

9. National High Blood Pressure Education Program. The Seventh Report of the Joint National Committee on Prevention, Detection, Evaluation, and Treatment of High Blood Pressure (JNC7). Available from: http://www.ncbi.nlm.nih.gov/books/ NBK9630/pdf/Bookshelf_NBK9630.pdf. Accessed December 4, 2015.

10. Star SL, Griesemer JR. Institutional ecology, 'translations' and boundary objects: amateurs and professionals in Berkeley's Museum of Vertebrate Zoology, 1907-39. Soc Stud Sci 1989;19:387-420.

11. Feldman HJ, Walker J, Li J, Delbanco T. OpenNotes: hospitalists' challenge and opportunity. J Hosp Med 2013;8:414-7.

12. Nazi KM, Turvey CL, Klein DM, Hogan TP, Woods SS. VA OpenNotes: exploring the experiences of early patient adopters with access to clinical notes. J Am Med Inform Assoc 2015;22:380-9.

13. Piper M, Evans C, Burda B, Margolis K, O'Connor E, Whitlock E. Diagnostic and predictive accuracy of blood pressure screening methods with consideration of rescreening intervals: an updated systematic review for the U.S. Preventive Services Task Force. Ann Intern Med 2015;162: 192-204.

14. Siu AL; U.S. Preventive Services Task Force. Screening for high blood pressure in adults: U.S. Preventive Services Task Force recommendation statement. Ann Intern Med 2015;163:778-86.

15. Campbell NR, Niebylski ML, Redburn K, et al. World Hypertension League position on public use of blood pressure kiosks. J Clin Hypertens (Greenwich) 2015;17:913.

16. Carter BU, Kaylor MB. The use of ambulatory blood pressure monitoring to confirm a diagnosis of high blood pressure by primary-care physicians in Oregon. Blood Press Monit 2016;21:95-102. 


\section{Appendix 1}

\section{Focus Group Protocol}

Section I: Workflow

I'd like to start by discussing the workflow in the clinic now that the PharmaSmart kiosks have been in place for months.

1. How does the use of the kiosk fit in with patient flow from the time a patient enters the clinic to the time a patient is roomed?

a. What is the sequence of events?

b. Does the patient taking his/her own blood pressure affect clinic flow?

2. Have problems with workflow arisen?

a. If yes: What kind of problems? How were those problems solved? What solutions were developed?

b. How does directing patients to the kiosk affect front desk workflow?

3. What process is being used to transfer the blood pressure and pulse from the kiosk printout to patient charts?

a. How do you think this process is working?

b. Have problems with the transfer arisen?

i. Ifyes: What kind of problems? How were those problems solved? What solutions were developed?

4. Without mentioning any names, can you tell me about the experiences of any patients who have been unable to use the kiosk?

a. How has obtaining the vital signs for these patients been handled?

5. What happens if the kiosk blood pressure is high? low?

a. What if the pulse is high? low?

6. To what degree do you think the implementation of the kiosks has freed up time for the medical assistants?

a. How much time do think has been freed up in an average day?

b. What are the medical assistants doing with the added time?

c. For those of you who are medical assistants or front desk staff, how do you feel about the idea of shifting responsibility for taking vital signs to the kiosk to free up medical assistants' time for other activities?

d. For those of you who are physicians, how do you feel about the idea of shifting responsibility for taking vital signs to the kiosk to free up medical assistants' time for other activities?

\section{Section II: Acceptability}

I'd now like to hear about your opinions of the new clinic process in which patients measure their own blood pressure and pulse using the PharmaSmart kiosk.

7. What, in your opinion, has been good about the new clinic process in which patients measure their own blood pressure and pulse using the PharmaSmart kiosk?

8. What concerns do you have about the new clinic process in which patients measure their own blood pressure and pulse using the PharmaSmart kiosk?

a. Are there additional concerns that providers have? What about medical assistants? What about other staff and administrators?

9. Do you trust the blood pressures and pulses taken by the kiosk?

a. If participants communicate mistrust in the kiosk to take accurate blood pressures and pulses, ask: Why is that? What would make you feel more trustful of the kiosk measurements?

10. What proportion of patients do you think are taking their own vital signs?

a. Do you think patients feel comfortable taking their own blood pressures and pulses?

11. What concerns have patients raised to staff and/or their physicians about the new clinic process in which patients measure their own blood pressure and pulse using the PharmaSmart kiosk?

***The remaining questions will only be asked during the second focus group discussion.**

12. For those of you who are medical assistants or front desk staff, how do you feel now that you have experience with the clinic process in which patients measure their own blood pressure and pulse using the PharmaSmart kiosk?

a. What do you like about the clinic process in which patients measure their own blood pressure and pulse using the Phar- 
maSmart kiosk? What don't you like about the clinic process in which patients measure their own blood pressure and pulse using the PharmaSmart kiosk?

b. What was your best experience with the clinic process in which patients measure their own blood pressure and pulse using the PharmaSmart kiosk? Why? Your worst? Why?

13. For those of you who are physicians, how do you feel now that you have experience with the clinic process in which patients measure their own blood pressure and pulse using the PharmaSmart kiosk?

a. What do you like about the clinic process in which patients measure their own blood pressure and pulse using the PharmaSmart kiosk? What don't you like about the clinic process in which patients measure their own blood pressure and pulse using the PharmaSmart kiosk?

b. What was your best experience with the clinic process in which patients measure their own blood pressure and pulse using the PharmaSmart kiosk? Your worst? Why?

\section{Section III: Feasibility and Long-Term Use}

I'd now like to hear your opinions about the feasibility and long-term use of the kiosks.
14. What changes would you like to see in the clinic process in which patients measure their own blood pressure and pulse using the PharmaSmart kiosk?

a. What would you do differently next time?

15. What has been most surprising about the clinic process in which patients measure their own blood pressure and pulse using the PharmaSmart kiosk?

16. Imagine that technology and money are not limiting factors. What would you want from a future kiosk?

17. Would the clinic process in which patients measure their own blood pressure and pulse using the PharmaSmart kiosk, as it stands now, work long-term?

a. If yes: Why?

b. If no: What would have to change for you to reconsider your opinion?

18. What are the problems that you see currently in blood pressure measurement in the clinic?

a. What role does the kiosk have in helping with these problems?

\section{Conclusion}

19. Is there anything else you think we should know about your thoughts on the clinic process in which patients measure their own blood pressure and pulse using the PharmaSmart kiosk that we have not yet discussed? 


\section{Appendix 2}

\section{- FAMILY MEDICINE 口 OF YAKIMA}

\section{FAMILY MEDICINE OF YAKIMA KIOSK SURVEY}

Family Medicine of Yakima is working with the University of Washington on a research project to understand how patients experience using the new blood pressure kiosk in the waiting area. The results of this survey will help us provide better care to patients.

- Please take a moment to fill out this short questionnaire so we can better serve you as a patient in the future.

- Your answers are anonymous, which means that they cannot be traced back to you in any way.

- Your doctors and nurses will not see your answers.

- Taking part in this study is voluntary. This means that you can choose whether or not to fill out the survey.

- You do not have to answer any questions you do not want to answer.

\section{PLEASE DO NOT FILL OUT THIS FORM IF: \\ (1) You are 17 years of age or younger \\ (2) You have already filled out this form \\ When you finish the survey, please put it in the drop box by the front desk.}

- If you have questions about the kiosk, please contact the Family Medicine of Yakima Clinic Administrator at 509-966-9480.

- If you have questions about the research, please contact: LauraMae Baldwin, MD, MPH at 206-685-4799 or Imb@uw.edu.

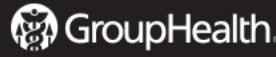 RESEARCH INSTITUTE}

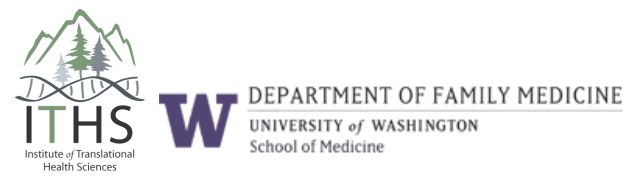

1. Have you taken your blood pressure on Family Medicine of Yakima's blood pressure kiosk or any other kiosk before?

Yes No

2. Did you take your blood pressure at Family Medicine of Yakima's blood pressure kiosk today?
Yes
No

If NO, why not? (Please skip to question 5):

3. How comfortable did you feel using the kiosk? (check one)
$\square$ Very

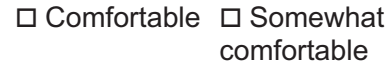 $\square$ Not very
comfortable
$\square$ Not at all
comfortable comfortable 
4. How confident were you that you could use the kiosk to take your blood pressure on your own? (check one)

\begin{tabular}{|c|c|c|c|}
\hline $\begin{array}{l}\text { Very } \\
\text { onfident }\end{array}$ & $\square$ Confident & $\begin{array}{l}\square \text { Somewhat } \\
\text { confident }\end{array}$ & $\begin{array}{l}\square \text { Not very } \\
\text { confident }\end{array}$ \\
\hline
\end{tabular}

5. How comfortable were you with being asked to use the kiosk to take your blood pressure rather than having the nurse or medical assistant take it? (check one)

\begin{tabular}{|c|c|c|c|}
\hline $\begin{array}{l}\square \text { Very } \\
\text { comfortable }\end{array}$ & $\square$ Comfortable & $\begin{array}{l}\square \text { Somewhat } \\
\text { comfortable }\end{array}$ & $\begin{array}{l}\square \text { Not very } \\
\text { comfortable }\end{array}$ \\
\hline
\end{tabular}

6. What did you like about using the kiosk?

7. What one thing could we have done better today to improve your experience using the kiosk?

8. I think my blood pressure results from the kiosk were:

More accurate than when a staff member (medical assistant or nurse) takes them

As accurate as when a staff member takes them

Less accurate than when a staff member takes them

If you think the results were more accurate or less accurate, why is that?

9. Did a health care provider (for example, nurse, medical assistant, doctor) take your blood pressure at your visit today? (check one)

Yes, a healthcare provider took my blood pressure today

No, a healthcare provider did not take my blood pressure today.

If NO:

Have you seen a healthcare provider yet? $\square$ Yes $\square$ No

10. Is there anything else you would like us to know about your experience with the kiosk?

When you finish the survey, please put it in the drop box by the front desk. Thank you! 
11. Did the receptionist in the waiting room improve your experience with using the kiosk?

Yes $\square$ No

If YES, please explain how

12. What one thing could the receptionist in the waiting room have done to make your experience today better?

13. Clinic staff members save time when you take your own blood pressure on the kiosk. Family Medicine of Yakima is using this time to better manage your overall health. Please tell us how you feel about this.

14. Do you think that Family Medicine of Yakima should keep using the kiosk?

Yes If YES, why?

No If NO, why not?

15. Is there anything else you would like us to know about your experience with the kiosk? 


\section{When you finish the survey, please put it in the drop box by the front desk. Thank you!

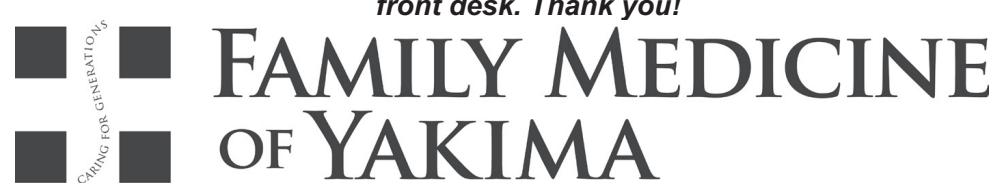

FAMILY MEDICINE OF YAKIMA KIOSK SURVEY

Family Medicine of Yakima is working with the University of Washington on a research project to understand how patients experience using the new blood pressure kiosk in the waiting area. The results of this survey will help us provide better care to patients.

- Please take a moment to fill out this short questionnaire so we can better serve you as a patient in the future.

- Your answers are anonymous, which means that they cannot be traced back to you in any way.

- Your doctors and nurses will not see your answers.

- Taking part in this study is voluntary. This means that you can choose whether or not to fill out the survey.

- You do not have to answer any questions you do not want to answer.

PLEASE DO NOT FILL OUT THIS FORM IF:

(1) You are 17 years of age or younger

(2) You already filled out this form in the last month

When you finish the survey,

please put it in the drop box by the front desk.

- If you have questions about the kiosk, please contact the Family Medicine of Yakima Clinic Administrator at 509-966-9480.

- If you have questions about the research, please contact: LauraMae Baldwin, MD, MPH at 206-685-4799 or Imb@uw.edu.

\section{(8.8. GroupHealth.}

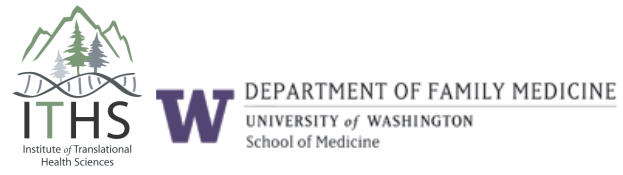

1. Have you taken your blood pressure on Family Medicine of Yakima's blood pressure kiosk or any other kiosk before?

$\square$ Yes $\square$ No

2. Did you take your blood pressure at Family Medicine of Yakima's blood pressure kiosk today?

$\square$ Yes $\square$ No

If NO, why not? (Please skip to question 5):

3. How comfortable did you feel using the kiosk? (check one)
$\square$ Very
comfortable
$\square$ Comfortable
$\square$ Somewhat
comfortable
$\square$ Not very
$\square$ Not at all comfortable
comfortable 
4. How confident were you that you could use the kiosk to take your blood pressure on your own? (check one)

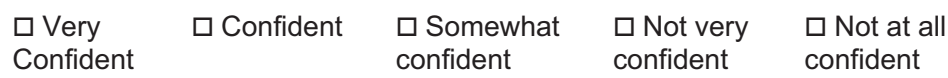

5. How comfortable were you with being asked to use the kiosk to take your blood pressure rather than having the nurse or medical assistant take it? (check one)
$\square$ Very
$\square$ Comfortable
$\square$ Somewhat
$\square$ Not very
$\square$ Not at all comfortable comfortable
comfortable
comfortable

6. What did you like about using the kiosk?

7. What one thing could we have done better today to improve your experience using the kiosk?

8. I think my blood pressure results from the kiosk were:

More accurate than when a staff member (medical assistant or nurse) takes them

As accurate as when a staff member takes them

Less accurate than when a staff member takes them

If you think the results were more accurate or less accurate, why is that?

9. Did a health care provider (for example, nurse, medical assistant, doctor) take your blood pressure at your visit today? (check one)

Yes, a healthcare provider took my blood pressure today

$\square$ No, a healthcare provider did not take my blood pressure today.

If NO:

Have you seen a healthcare provider yet? $\square$ Yes $\square$ No

10. Did a receptionist in the waiting room help you with using the kiosk today?

$\square$ Yes $\quad \square$ No If NO, please skip to question 13 . 